\title{
The influence of tart cherries (Prunus Cerasus) on vascular function and the urinary metabolome: a randomised placebo-controlled pilot study
}

\author{
Rachel Kimble ${ }^{1}$, Lucy Murray ${ }^{1}$, Karen M. Keane ${ }^{1}$, Karen Haggerty ${ }^{2}$, Glyn Howatson ${ }^{1}$ and \\ John K. Lodge ${ }^{2 *}$ (1) \\ ${ }^{1}$ Department of Sport, Exercise and Rehabilitation, Faculty of Health and Life Sciences, Northumbria University, Newcastle-upon-Tyne, UK \\ ${ }^{2}$ Department of Applied Sciences, Faculty of Health and Life Sciences, Northumbria University, Newcastle-upon-Tyne, UK
}

(Received 20 April 2021 - Final revision received 11 August 2021 - Accepted 19 August 2021)

Journal of Nutritional Science (2021), vol. 10, e73, page 1 of 5

doi: $10.1017 /$ jns. 2021.68

Abstract

Montmorency tart cherries (MC) have been found to modulate indices of vascular function with interventions of varying duration. The objective of this preliminary study was to identify the chronic effects of $\mathrm{MC}$ supplementation on vascular function and the potential for urinary metabolomics to provide mechanistic evidence. We performed a placebo-controlled, double-blind, randomised study on 23 healthy individuals (18M, $7 \mathrm{~F}$ ) that consumed $30 \mathrm{ml} \mathrm{MC}$ or a placebo twice daily for 28 days. Whole body measures of vascular function and spot urine collections were taken at baseline and after supplementation. There were no significant changes to vascular function including blood pressure and arterial stiffness. Urinary metabolite profiling highlighted significant changes $(P<0.001)$ with putative discriminatory metabolites related to tryptophan and histidine metabolism. Overall, MC supplementation for 28 days does not improve indices of vascular function but changes to the urinary metabolome could be suggestive of potential mechanisms.

Key words: Anthocyanin: Arterial stiffness: Blood pressure: Cherry: Metabolomics

\section{Introduction}

Cardiovascular disease (CVD) is the primary cause of morbidity and mortality ${ }^{(1)}$. Preclinical studies suggest that Montmorency tart cherries (MC) can positively impact major risk factors of CVD, activities thought to be related to their phytochemical content $^{(2)}$. However, data from human trials are less clear. MC have been shown to reduce systolic blood pressure (SBP) after acute $^{(3,4)}$, short-term ${ }^{(5)}$ and chronic $^{(6)}$ intake and to improve vascular dysfunction ${ }^{(7)}$, reduce LDL-cholesterol ${ }^{(6)}$ and oxidised $\mathrm{LDL}^{(8)}$, presumably due to their antioxidant and antiinflammatory activities ${ }^{(2)}$. Notwithstanding, other studies have not shown the benefits of MC on SBP or vascular function ${ }^{(8-10)}$. Studies are difficult to interpret with different populations, dosing and durations but we have previously demonstrated that a dosing regimen of $30 \mathrm{ml}$ twice daily (equivalent to $60 \mathrm{ml} / \mathrm{d}$ ) significantly affected vascular function in mildly hypertensive males $^{(3)}$ and middle-aged adults ${ }^{(4)}$. There is also a lack of understanding for any underlying mechanisms, and to provide mechanistic evidence, the use of metabolomics has become increasingly popular. For example, metabolomics have shown that anthocyanin-rich interventions increase circulating polyphenol metabolites that might account for improvements in vascular function ${ }^{(11)}$. Therefore, the aim of this preliminary study was to characterise the effects of MC supplementation with an effective dosage regimen on vascular function with a 4-week intervention and explore if metabolomics can provide mechanistic evidence.

\section{Methods}

A power calculation was performed for the primary outcome systolic blood pressure. According to the previous study ${ }^{(3)}$ and

* Corresponding author: John K. Lodge, email john.lodge@northumbria.ac.uk 
Table 1. Baseline characteristics of participants

\begin{tabular}{lccr}
\hline & Tart cherry group $(n 12)$ & Placebo group $(n 11)$ & $P$-value \\
\hline Sex $(\mathrm{m} / \mathrm{f}, n)$ & $9 / 3$ & $8 / 3$ & - \\
Age $($ years $)$ & $24.7 \pm 3.6$ & $22.0 \pm 2$ & 0.03 \\
BMI $\left(\mathrm{kg} / \mathrm{m}^{2}\right)$ & $24.6 \pm 3.2$ & $24.6 \pm 2 \cdot 3$ & 0.98 \\
SBP & $124.1 \pm 10.7$ & $119.6 \pm 10.7$ & 0.32 \\
DBP & $67.6 \pm 5.6$ & $65.1 \pm 6.7$ & 0.11 \\
\hline
\end{tabular}

using a population standard deviation of $11 \mathrm{~mm} \mathrm{Hg}$ at $80 \%$ power and $5 \%$ significance, the minimum number of participants required to allow detection of a difference of $5 \mathrm{~mm} \mathrm{Hg}$ (clinically relevant outcome) between the responses to the two intervention drinks was estimated to be 12 . Twenty-three healthy non-smoking volunteers, who did not regularly consume cherries, use antioxidant supplements or medications, took part in the present randomised (http://randomisation. eu/index.shtml), double-blind, placebo-controlled, parallel study. Participants attended the laboratory on two separate occasions. Participants' vascular function measures and spot urine samples ${ }^{(12)}$ were collected following an overnight fast $(\geq 12 \mathrm{~h}$ ) pre and post 4 -week supplementation with either MC concentrate $(\mathrm{m} / \mathrm{f}: 9 / 3)$ or an isocaloric placebo $(\mathrm{m} / \mathrm{f}$ : $8 / 3)$. Baseline characteristics are shown in Table 1 and there was a significant difference in age $(P=0 \cdot 03)$. Participants maintained their habitual diet apart from following a low phenolic diet for $48 \mathrm{~h}$ before each laboratory visit. Participants consumed $30 \mathrm{ml}$ of an $\mathrm{MC}$ concentrate (CherryActive, UK; containing $36.8 \mathrm{mg}$ of anthocyanins (as cyanidin-3 glucoside equivalents using the $\mathrm{pH}$ differential colorimetric method) as well as several hydroxycinnamic and hydroxybenzoic acids) diluted in $100 \mathrm{ml}$ of water or the same amount of placebo twice daily, once in the morning and evening. The placebo was a low fruit $(<1 \%)$ unsweetened black cherry cordial mixed with ingredients to match MC concentrate for energy and macronutrients (Per $130 \mathrm{ml}$, energy $102 \mathrm{kcal}$, carbohydrate $24.5 \mathrm{~g}$, protein $1.1 \mathrm{~g}$ and fat $0 \mathrm{~g}$ ), colour and taste as described ${ }^{(3,4)}$. No adverse effects were reported and average self-reported compliance was $86 \%$. This study was conducted according to the guidelines laid down in the Declaration of Helsinki and all procedures were ratified by Northumbria University's Research Ethics Committee, and participants provided written informed consent. The trial conforms to CONSORT standards and is registered with ClinicalTrials.gov, identifier NCT04840160.

Vascular function was assessed as we have detailed elsewhere ${ }^{(13)}$ using appropriate commercial devices for blood pressure and heart rate (HR) (M10-IT; Omron Healthcare), pulse wave velocity (PWV) (SphygmoCor CPV system ScanMed Medical, UK) and Digital Volume Pulse (DVP) (Pulse'Trace PCA 2 with a photoplethysmograph transducer, MicroMedical, UK). Urine samples were prepared for metabolomic analysis as described ${ }^{(12)}$ following standardisation by refractive index. Hydrophilic interaction liquid chromatography (HILIC) analysis was deemed more appropriate for a more polar biological fluid such as urine. HILIC was conducted using ultrahigh resolution liquid chromatography (UHPLC) and mass spectrometry (MS) (adapted from Langer et al. ${ }^{(12)}$ ) and data acquisition parameters, data processing and data mining information are detailed in the online supplementary methods. Statistical analysis was conducted using SPSS for windows (V24.0: Chicago, IL). A two-way repeatedmeasures ANOVA analysed the effect of time, treatment and time $\times$ treatment interactions for vascular function measures.

Table 2. Influence of Montmorency cherry concentrate on vascular function

\begin{tabular}{|c|c|c|c|c|c|c|c|}
\hline & \multirow{2}{*}{$\begin{array}{l}\text { Montmorency } \\
\text { cherry }(n 12)\end{array}$} & \multirow{2}{*}{$\begin{array}{c}\text { Change from } \\
\text { mean (\% change) }\end{array}$} & \multirow{2}{*}{$\begin{array}{l}\text { Placebo } \\
(n 11)\end{array}$} & \multirow{2}{*}{$\begin{array}{c}\text { Change from } \\
\text { mean (\% change) }\end{array}$} & \multicolumn{3}{|c|}{$P$-value for ANOVA } \\
\hline & & & & & Treatment & Time & Interaction \\
\hline \multicolumn{8}{|c|}{$\mathrm{SBP}(\mathrm{mmHg})$} \\
\hline Baseline & $124 \cdot 1 \pm 10 \cdot 7$ & \multirow[t]{2}{*}{$-3.57 \pm 10.2(0.03 \%)$} & $119 \cdot 6 \pm 10 \cdot 7$ & \multirow[t]{2}{*}{$1.82 \pm 3.5(-0.03 \%)$} & \multirow[t]{2}{*}{0.21} & \multirow[t]{2}{*}{0.18} & \multirow[t]{2}{*}{0.84} \\
\hline 4 weeks & $127 \cdot 5 \pm 16 \cdot 4$ & & $121 \cdot 8 \pm 11 \cdot 1$ & & & & \\
\hline \multicolumn{8}{|c|}{$\mathrm{DBP}(\mathrm{mmHg})$} \\
\hline Baseline & $67 \cdot 6 \pm 5 \cdot 6$ & \multirow[t]{2}{*}{$-0.83 \pm 7.1(0.01 \%)$} & $65 \cdot 1 \pm 6 \cdot 7$ & \multirow[t]{2}{*}{$-2.18 \pm 12.8(0.02 \%)$} & \multirow[t]{2}{*}{0.28} & \multirow[t]{2}{*}{0.12} & \multirow[t]{2}{*}{0.58} \\
\hline 4 weeks & $66 \cdot 8 \pm 6 \cdot 3$ & & $63 \cdot 3 \pm 7.9$ & & & & \\
\hline \multicolumn{8}{|c|}{ MAP (mmHg) } \\
\hline Baseline & $86 \cdot 5 \pm 4 \cdot 4$ & \multirow[t]{2}{*}{$-1.7 \pm 5.9(0.02 \%)$} & $83 \cdot 3 \pm 6 \cdot 9$ & \multirow[t]{2}{*}{$0.5 \pm 6 \cdot 2(0.01 \%)$} & \multirow[t]{2}{*}{0.07} & \multirow[t]{2}{*}{0.97} & \multirow[t]{2}{*}{0.67} \\
\hline 4 weeks & $87 \cdot 0 \pm 7.5$ & & $82 \cdot 8 \pm 7 \cdot 7$ & & & & \\
\hline \multicolumn{8}{|l|}{ HR (BPM) } \\
\hline Baseline & $66 \cdot 7 \pm 14 \cdot 1$ & \multirow[t]{2}{*}{$-4.33 \pm 12.9(0.09 \%)$} & $66 \cdot 5 \pm 10 \cdot 1$ & \multirow[t]{2}{*}{$-1.5 \pm 6.1(0.03 \%)$} & \multirow[t]{2}{*}{0.71} & \multirow[t]{2}{*}{0.25} & \multirow[t]{2}{*}{0.75} \\
\hline 4 weeks & $69 \cdot 8 \pm 11 \cdot 2$ & & $68 \cdot 0 \pm 9 \cdot 2$ & & & & \\
\hline \multicolumn{8}{|l|}{ PWV (m/s) } \\
\hline Baseline & $5.5 \pm 0.7$ & \multirow[t]{2}{*}{$-0.22 \pm 0.94(0.05 \%)$} & $5 \cdot 7 \pm 1 \cdot 3$ & \multirow[t]{2}{*}{$0.96 \pm 1.82(-0.17 \%)$} & \multirow[t]{2}{*}{0.72} & \multirow[t]{2}{*}{0.36} & 0.2 \\
\hline 4 weeks & $6 \cdot 1 \pm 1 \cdot 2$ & & $5 \cdot 6 \pm 0 \cdot 8$ & & & & \\
\hline DVP-SI $(\mathrm{m} / \mathrm{s}$ & & & & & & & \\
\hline Baseline & $6 \cdot 0 \pm 0 \cdot 8$ & $-0.02 \pm 0.51(0.17 \%)$ & $5 \cdot 6 \pm 0 \cdot 7$ & $0.23 \pm 0.51(0.17 \%)$ & 0.19 & 0.45 & 0.24 \\
\hline 4 weeks & $6 \cdot 0 \pm 0.9$ & & $5 \cdot 4 \pm 0.5$ & & & & \\
\hline DVP-RI (\%) & & & & & & & \\
\hline Baseline & $62 \cdot 4 \pm 13 \cdot 4$ & $-2 \cdot 27 \pm 16 \cdot 3(0.02 \%)$ & $51 \cdot 4 \pm 10 \cdot 6$ & $-5.4 \pm 9.8(0.02 \%)$ & 0.12 & 0.22 & 0.56 \\
\hline 4 weeks & $63 \cdot 5 \pm 15 \cdot 9$ & & $56 \cdot 8 \pm 8 \cdot 6$ & & & & \\
\hline
\end{tabular}

Values are mean \pm SD for SBP, DBP, MAP, HR, PWV, DVP-SI, DVP-RI.

SBP, systolic blood pressure; DBP, diastolic blood pressure; MAP, mean arterial pressure; HR, heart rate; PWV, pulse wave velocity; DVP-SI, digital volume pulse stiffness index; DVP-RI, digital volume pulse reflection index. 

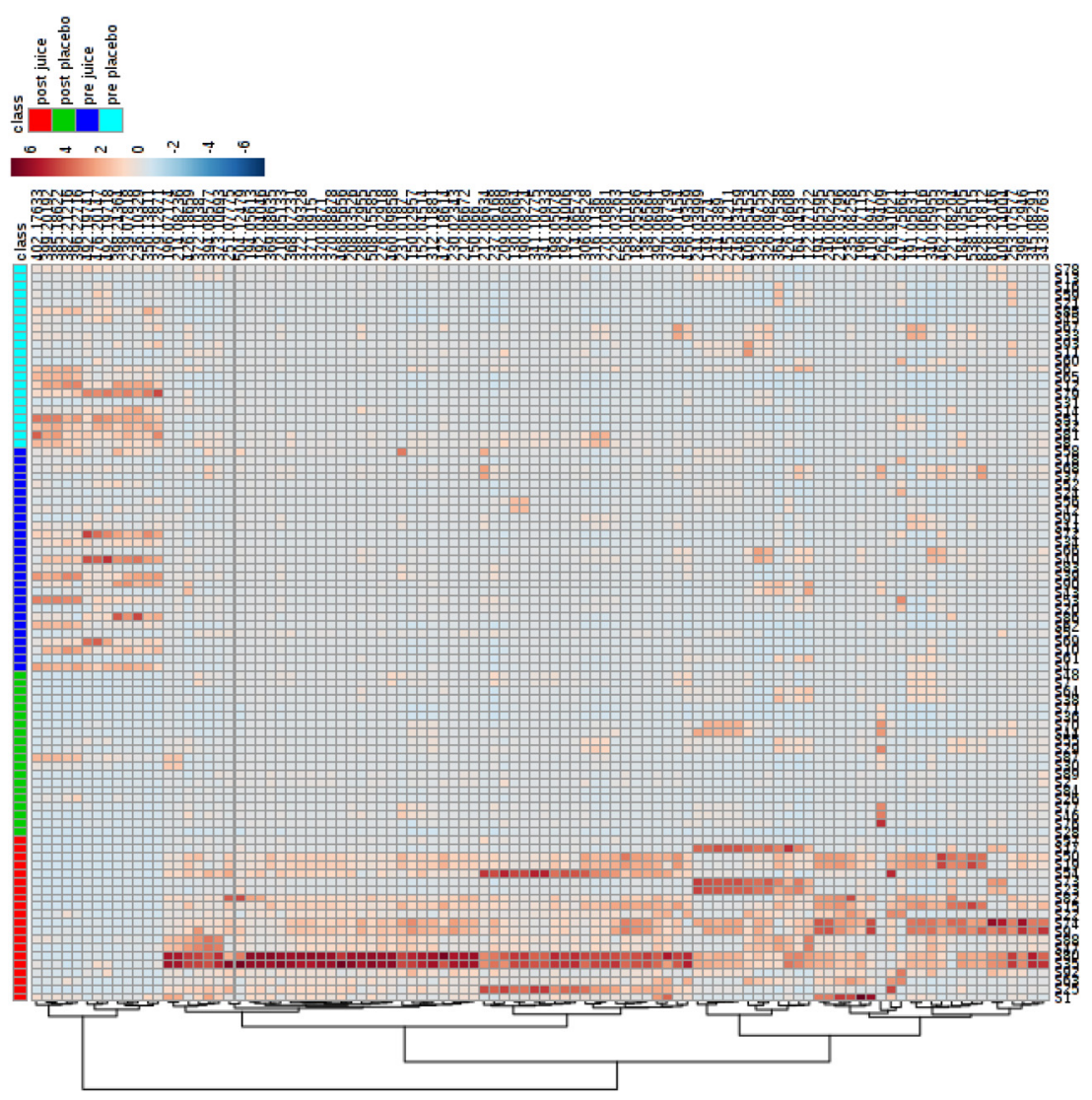

a

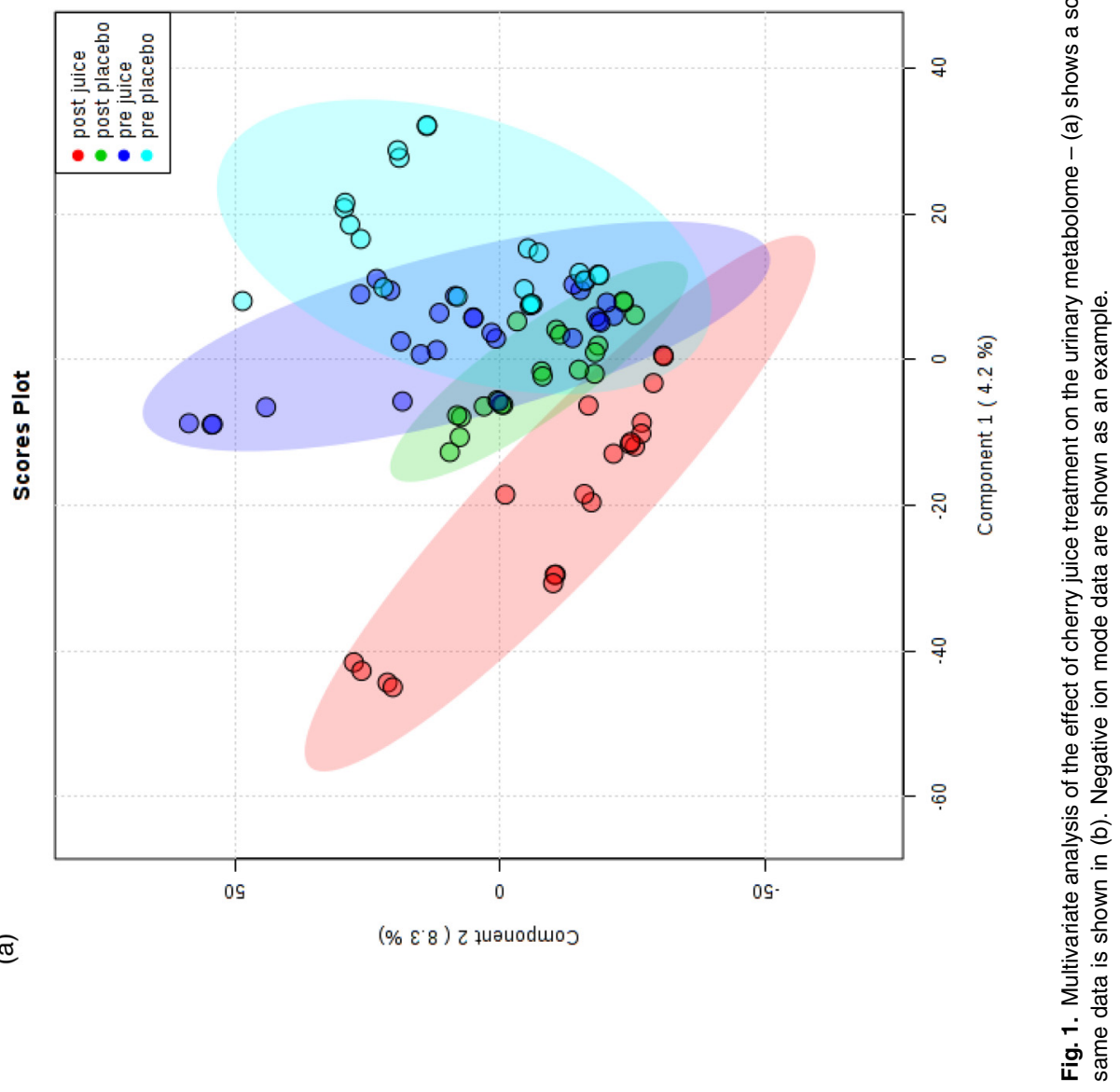


Table 3. Putative identifications of highly ranked discriminating metabolites following tart cherry juice supplementation

\begin{tabular}{|c|c|c|c|c|c|c|c|c|}
\hline Annotation & $\begin{array}{l}\text { Predicted } \\
\text { formula }\end{array}$ & VIP & $m / z$ & Adduct & $\begin{array}{l}\text { Mass error } \\
\text { (PPM) }\end{array}$ & $\begin{array}{l}\text { lon } \\
\text { mode }\end{array}$ & Change & ID \\
\hline \multirow[t]{3}{*}{$N$-Methyltryptamine } & \multirow[t]{3}{*}{$\mathrm{C} 11 \mathrm{H} 14 \mathrm{~N} 2$} & $3 \cdot 38$ & $207 \cdot 14912$ & $\mathrm{M}+\mathrm{CH}_{3} \mathrm{OH}+\mathrm{H}$ & 0 & + & $\downarrow$ & \multirow[t]{3}{*}{ HMDB0004370 } \\
\hline & & $3 \cdot 26$ & $207 \cdot 14904$ & $\mathrm{M}+\mathrm{CH}_{3} \mathrm{OH}+\mathrm{H}$ & 1 & + & $\downarrow$ & \\
\hline & & 3.07 & $235 \cdot 18057$ & $\mathrm{M}+$ IsoProp $+\mathrm{H}$ & 2 & + & $\downarrow$ & \\
\hline 5-Methoxydimethyltryptamine & $\mathrm{C} 13 \mathrm{H} 18 \mathrm{~N} 2 \mathrm{O}$ & $2 \cdot 65$ & $251 \cdot 17564$ & $\mathrm{M}+\mathrm{CH}_{3} \mathrm{OH}+\mathrm{H}$ & 1 & + & $\downarrow$ & HMDB0002004 \\
\hline 5-Methoxytryptamine & $\mathrm{C} 11 \mathrm{H} 14 \mathrm{~N} 2 \mathrm{O}$ & & & $\mathrm{M}+\mathrm{IsoProp}+\mathrm{H}$ & 1 & + & $\downarrow$ & HMDB0004095 \\
\hline \multirow[t]{2}{*}{ Nb-Acetyl-Nb-methyltryptamine } & \multirow[t]{2}{*}{$\mathrm{C} 13 \mathrm{H} 16 \mathrm{~N} 2 \mathrm{O}$} & $3 \cdot 65$ & $249 \cdot 16001$ & $\mathrm{M}+\mathrm{CH}_{3} \mathrm{OH}+\mathrm{H}$ & 1 & + & $\downarrow$ & \multirow[t]{2}{*}{ HMDB0029837 } \\
\hline & & 3.43 & $249 \cdot 16017$ & $\mathrm{M}+\mathrm{CH}_{3} \mathrm{OH}+\mathrm{H}$ & 2 & + & $\downarrow$ & \\
\hline \multirow[t]{2}{*}{ Melatonin } & \multirow[t]{2}{*}{$\mathrm{C} 13 \mathrm{H} 16 \mathrm{~N} 2 \mathrm{O} 2$} & $2 \cdot 66$ & $233 \cdot 16493$ & $\mathrm{M}+\mathrm{H}$ & 0 & + & $\downarrow$ & \multirow[t]{2}{*}{ HMDB0001389 } \\
\hline & & $1 \cdot 10$ & $296 \cdot 13704$ & $\mathrm{M}+\mathrm{ACN}+\mathrm{Na}$ & 0 & + & $\downarrow$ & \\
\hline \multirow[t]{3}{*}{ 6-Hydroxymelatonin } & \multirow[t]{3}{*}{$\mathrm{C} 13 \mathrm{H} 16 \mathrm{~N} 2 \mathrm{O} 3$} & $1 \cdot 17$ & $271 \cdot 10589$ & $\mathrm{M}+\mathrm{Na}$ & 2 & + & $\downarrow$ & \multirow[t]{3}{*}{ HMDB0004081 } \\
\hline & & 1.05 & $249 \cdot 12377$ & $\mathrm{M}+\mathrm{H}$ & 2 & + & $\downarrow$ & \\
\hline & & $3 \cdot 76$ & $205 \cdot 13356$ & $\mathrm{M}-\mathrm{CO}_{2}+\mathrm{H}$ & 1 & + & $\downarrow$ & \\
\hline 5-Hydroxyindoleacetate & $\mathrm{C} 10 \mathrm{H} 11 \mathrm{NO} 2$ & $4 \cdot 24$ & 194.05986 & $\mathrm{M}+\mathrm{H}$ & 1 & + & $\uparrow$ & HMDB0000763 \\
\hline 1-Methylhistidine & $\mathrm{C} 5 \mathrm{H} 6 \mathrm{~N} 2 \mathrm{O}$ & 3.8469 & $150 \cdot 06697$ & $\mathrm{M}-\mathrm{H}_{2} \mathrm{O}-\mathrm{H}$ & 1 & - & $\uparrow$ & HMDB0000001 \\
\hline L-histidine & C6N9N3O2 & $4 \cdot 2199$ & $136 \cdot 05121$ & $\mathrm{M}-\mathrm{H}_{2} \mathrm{O}-\mathrm{H}$ & 1 & - & $\uparrow$ & HMDB0000177 \\
\hline $\mathrm{N}, \mathrm{N}$-dimethylhistidine & C6H8N2O & $3 \cdot 1115$ & $164 \cdot 08275$ & {$\left[\mathrm{M}-\mathrm{H}_{2} \mathrm{O}-\mathrm{H}\right]-$} & 1 & - & $\downarrow$ & HMDB0033438 \\
\hline
\end{tabular}

VIP, variable importance in projection.

Baseline characteristics were compared between groups by an unpaired $t$ test. The $\alpha$ level for statistical significance was set at 0.05 a priori.

\section{Results and discussion}

Despite accumulating evidence for the potential role of cherries in cardiovascular health ${ }^{(2)}$, the exact mechanisms have yet to be fully elucidated. Thus, we incorporated a metabolomic approach to explore potential mechanisms. We found $\mathrm{MC}$ concentrate to have no significant effect on our indices of vascular function (SBP, diastolic blood pressure, MAP, HR, PWV, DVP-SI or DVP-RI) compared to the placebo after the intervention $(P>0 \cdot 05$; Table 2$)$ with only minor changes from baseline, in line with evidence that MC has no effect on vascular function in normotensive individuals ${ }^{(8-10,14)}$, even those with higher doses ${ }^{(15)}$ or longer duration $^{(14,15)}$. MC concentrate has been repeatedly shown to result in transient reductions in SBP that return to baseline within $3-4 \mathrm{~h}^{(3)}$. Since this study investigated vascular function after an overnight fast it is possible that any changes in BP were missed due to the seemingly rapid absorption and/or excretion of tart cherry anthocyanin metabolites ${ }^{(16)}$. It is likely that a combination of dose, duration and population are responsible for the null effects. Durations between 20 days ${ }^{(5)}$ to 12 weeks ${ }^{(6)}$ have been reported with no association between duration and effect. There is a better likelihood of finding a change in a higher risk population, as in a recent review of factors influencing the effects of anthocyanins, both a higher initial BP and habitual flavonoid intake were identified as relevant determinants of efficacy ${ }^{(17)}$, and these are points to inform future studies with MC concentrate.

However, we did observe an influence on the urinary metabolome (Fig. 1). There was a good similarity between the metabolome of both treatments at baseline despite limited dietary restrictions and we were able to discriminate posttreatment MC concentrate samples (Fig. 1). Preliminary analysis of the top-ranked discriminatory features found 32 and
18 ion clusters in positive and negative mode, respectively, and Table 3 shows putative matches from these. These included metabolites from tryptophan metabolism (enrichment factor $7 \cdot 1,-\log 10(\mathrm{p}) 1.5)$ including 6-hydroxy melatonin, 5-hydroxyindoleacetate and melatonin in positive mode, while histidine metabolism was prominent in negative ion mode (enrichment factor 15.2, $-\log 10(\mathrm{p}) 1 \cdot 1$ ) suggesting an influence on tryptophan and histidine pathways even in the absence of changes to vascular function variables. For example, we observed a decrease in urinary excretion of melatonin and 6-hydroxymelatonin. Both tryptophan and melatonin are found in tart cherries ${ }^{(2)}$ and have been linked to improvements in sleep following MC supplementation as we have previously shown ${ }^{(18)}$. Moreover, melatonin and tryptophan metabolites might be beneficial to cardiovascular health because of their antioxidant, anti-inflammatory and antiatherogenic actions ${ }^{(19)}$, suggesting the properties of the indolamine compounds in MC warrant further attention. We also identified an increase in metabolites from the histidine pathway (e.g. histidine, methylated histidine), supporting a study supplementing anthocyanin-rich red wine that resulted in increases in urinary 1-methylhistidine ${ }^{(20)}$. We also found matches to expected exogenous metabolites, such as cyanidin glucosides, ferulic acid; however, these were not highly discriminatory, perhaps as they are rapidly cleared ${ }^{(16)}$. Although only preliminary findings, these data provide evidence that intakes of anthocyanin-rich beverages such as MC juice can influence amino acid metabolism and tentatively provide a mechanistic basis for their health effects, although in the present study these changes were not sufficient to elicit a physiological effect.

This study has limitations. We investigated a young, normotensive population, but individuals with higher CVD risk might benefit more from anthocyanin supplementation, or treatment with a longer duration and a higher dosing regimen and a larger number of participants. Notably, the population in the present study was not confounded by medications. Secondly, our dosing regimen was 4-week long and this duration may need to be extended, but importantly the intervention was well tolerated. 
Furthermore, a crossover study may be more optimal (and especially for metabolomics) as this would reduce interindividual variation. This study suggests that consumption of $\mathrm{MC}$ concentrate for 4 weeks does not influence indices of vascular function in healthy individuals. However, the intervention did induce changes to the urinary metabolome specific to amino acid metabolism and this is the first such report of this effect. These findings have important implications for the physiological effects of tart cherries. Future studies, with larger sample sizes, with higher risk populations and of longer duration are needed to fully elucidate the potential of this intervention but do suggest that metabolomics can be useful to identify metabolic changes indicative of mechanisms of action.

\section{Supplementary material}

The supplementary material for this article can be found at https://doi.org/10.1017/jns.2021.68

\section{Acknowledgments}

We would like to thank the Cherry Marketing Institute for funding this research through a joint funded studentship (RK) with Northumbria University and also to the participants in this study. This work was made possible by a grant award to $\mathrm{GH}$ by the Michigan Cherry Committee.

L.M. carried out the study as part of an MSc programme and was aided by K.K. G.H. was the principal investigator and conceived the study with J.K.L. K.H. performed sample extraction for metabolomic analysis, which was performed by R.K. and J. K.L. Statistical analysis was performed by R.K. All authors were responsible for the preparation of the manuscript.

Cherry Marketing Institute for funding this research through a joint funded studentship (RK) with Northumbria University. The authors declare no competing interests to disclose.

\section{References}

1. Townsend N, Wilson L, Bhatnagar P, et al. (2016) Cardiovascular disease in Europe: epidemiological update 2016. Eur Heart J 37, 3232-3245.

2. Kelley DS, Adkins Y \& Laugero KD (2018) A review of the health benefits of cherries. Nutrients 10, 368.

3. Keane KM, George TW, Constantinou CL, et al. (2016) Effects of Montmorency tart cherry (Prunus Cerasus L.) consumption on vascular function in men with early hypertension. Am J Clin Nutr 103, 1531-1539.

4. Keane KM, Haskell-Ramsay CF, Veasey RC, et al. (2016) Montmorency tart cherries (Prunus cerasus L.) modulate vascular function acutely, in the absence of improvement in cognitive performance. BrJ Nutr 116, 1935-1944.
5. Desai T, Roberts M \& Bottoms L (2021) Effects of short-term continuous Montmorency tart cherry juice supplementation in participants with metabolic syndrome. Eur J Nutr 60, 1587-1603.

6. Chai SC, Davis K, Wright RS, et al. (2018) Impact of tart cherry juice on systolic blood pressure and low-density lipoprotein cholesterol in older adults: a randomized controlled trial. Food Funct 9 , 3185-3194.

7. Aboo-Bakkar Z, Fulford J, Gates PE, et al. (2018) Montmorency cherry supplementation attenuates vascular dysfunction induced by prolonged forearm occlusion in overweight middle-aged men. J Appl Physiol.

8. Johnson SA, Navaei N, Pourafshar S, et al. (2020) Effects of montmorency tart cherry juice consumption on cardiometabolic biomarkers in adults with metabolic syndrome: a randomized controlled pilot trial. J Med Food 23, 1238-1247.

9. Desai T, Bottoms L \& Roberts M (2018) The effects of Montmorency tart cherry juice supplementation and FATMAX exercise on fat oxidation rates and cardio-metabolic markers in healthy humans. Eur J Appl Physiol 118, 2523-2539.

10. Martin KR, Burrell L \& Bopp J (2018) Authentic tart cherry juice reduces markers of inflammation in overweight and obese subjects: A randomized, crossover pilot study. Food Funct 9, $5290-5300$.

11. Istas G, Wood E, Le Sayec M, et al. (2019) Effects of aronia berry (poly) phenols on vascular function and gut microbiota: a double-blind randomized controlled trial in adult men. Am J Clin Nutr.

12. Langer S, Kennel A \& Lodge JK (2018) The influence of juicing on the appearance of blueberry metabolites $2 \mathrm{~h}$ after consumption: a metabolite profiling approach. Br J Nutr 119, 1233-1244.

13. Kimble R, Keane KM, Lodge JK, et al. (2019) Methodological considerations for a vascular function test battery. Int J Sports Med $\mathbf{4 0 ,}$ 601-608.

14. Lynn A, Mathew S, Moore CT, et al. (2014) Effect of a tart cherry juice supplement on arterial stiffness and inflammation in healthy adults: a randomised controlled trial. Plant Foods Hum Nutr 69, 122-127.

15. Johnson SA, Navaei N, Pourafshar S, et al. (2020) Effects of Montmorency tart cherry juice consumption on cardiometabolic biomarkers in adults with metabolic syndrome: a randomized controlled pilot trial. J Med Food 23, 1238-1247.

16. Keane KM, Bell PG, Lodge JK, et al. (2016) Phytochemical uptake following human consumption of Montmorency tart cherry (L. Prunus cerasus) and influence of phenolic acids on vascular smooth muscle cells in vitro. Eur J Nutr 55, 1695-1705.

17. Vendrame S \& Klimis-Zacas D (2019) Potential factors influencing the effects of anthocyanins on blood pressure regulation in humans: a review. Nutrients 11, 1431.

18. Howatson G, Bell PG, Tallent J, et al. (2012) Effect of tart cherry juice (Prunus cerasus) on melatonin levels and enhanced sleep quality. Eur J Nutr 51, 909-916.

19. Liu G, Chen S, Zhong J, et al. (2017) Crosstalk between tryptophan metabolism and cardiovascular disease, mechanisms, and therapeutic implications. Oxid Med Cell Longev. doi: 10.1155/2017/ 1602074. Epub 2017.

20. Jacobs DM, Fuhrmann JC, van Dorsten FA, et al. (2012) Impact of short-term intake of red wine and grape polyphenol extract on the human metabolome. J Agric Food Chem 60, 3078-3085. 